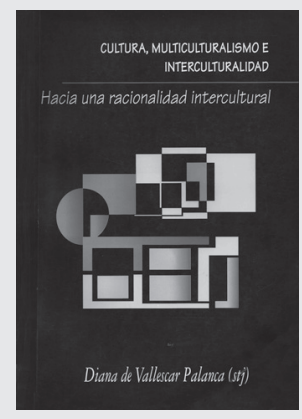

\title{
Cultura, Multiculturalismo e Interculturalidad. Hacia una racionalidad intercultural
}

Diana de Vallescar Palanca

Madrid, Editorial Perpetuo Socorro, 2000.

En Diana de Vallescar, encontramos una propuesta hacia una racionalidad intercultural que da cuenta de una ejercicio cognoscitivo provocativo para la filosofía, puesto que "se vuelve para interrogar su trayectoria históricogenética, su construcción, alcance y limites", en función de un análisis crítico de la realidad. Este análisis se presenta como un proceso realmente revolucionario, transformador de lo social, que busca transitar, junto con la razón, desde la coexistencia a la convivencia de los mundos, vale decir, el análisis crítico de los conceptos de cultura, culturalismo e interculturalidad son los núcleos para un estudio intercultural que nos permitiría construir un "paradigma cultural de versión múltiple", que se abre hacia la posibilidad de manejar varias conceptualizaciones.

La crisis en relación a la noción de cultura, esto que hemos denominado como lo provocativo y angular en una filosofía intercultural, traspasa las fronteras disciplinarias y se convierte en una discusión necesaria a nivel interdisciplinario, adelantándonos a la conceptualización de interculturalidad de Raúl Fornet Betancourt (capitulo 4). De Vallescar nos encamina hacia "la necesidad de replantear nuestros paradigmas de conocimiento" al dar cuenta de que nos encontramos frente a una crisis general en todas las disciplinas, en el marco de la posmodernidad, el abandono de los paradigmas dominantes, el surgimiento de mundos hasta ahora no vistos, el problema de una teoría social que no reacciona frente a las realidades que emergen frente a ella, configuran un espacio clave para las ciencias sociales y humanas, el momento de descentramiento, que se presenta como posibilidad de cambio, de ruptura epistemológica, "los descubrimientos de todo tipo, generan el desbordamiento del horizonte y la emergencia de sujetos hasta ahora desconocidos".

Siguiendo el trabajo de nuestra autora, podríamos señalar que si bien hemos descrito la crisis de la noción de cultura como uno de los detonantes del mundo moderno, frente al problema del otro y el rol de la civilización occidental en el concierto de la historia universal, deberíamos junto con esta afirmación hacer referencia de que nos encontramos frente a dos momentos distintos de la crisis de cultura, o del otro como problema. El primero de ellos se da en el marco de la Modernidad-Edad Media, en sus inicios (siglos XIV al XVII, Renacimiento y Humanismo), con el surgimiento de las nuevas geografías acompañadas de otras costumbres, de otros idiomas, nuevas historias, el cambio geopolítico llevó a Occidente hacia la "búsqueda de un nuevo discurso capaz de legitimar la propia condición europea y el estatuto del 'otro', recientemente descubierto", lo que generó la necesidad de pensar el mundo desde otra manera, pensar y vivir el mundo desde la conquista de la razón por 
la supremacía de la homogeneidad. Aquí nos encontramos con la "primera" de las rupturas epistemológicas, clave para entender la empresa colonizadora de ayer y de hoy: la actitud civilizadora de la Ilustración como materia prima de la empresa imperialista.

"La filosofía de la llustración... se orientó conforme al "plan de la razón" y la concepción del "precepto moral". Ya que la "razón" fue comprendida como el ser eterno, logos e historia, por consiguiente, contaba con la capacidad de hacer progresar infinitamente el género humano. Y su trayectoria se concibió en sentido lineal, es decir apuntando hacia el futuro".

Una lectura más acabada en torno a esta primera ruptura epistemológica debe ir acompañada de una mirada que permita dar cuenta de las sinergias históricas y "diversas" que fueron configurando la estructura de la razón como instrumento definitorio de lo humano. En este sentido habría que traer, junto con De Vallescar, la respuesta del historicismo, del romanticismo alemán frente a la Ilustración. Transitando del individuo a la noción de pueblo donde "la creación del universo cultural... es atribuida por la individualidad del pueblo", la patria, como coprotagonista en la creación de cultura y civilización, base para la estructura del Estado Nación.

"Con la emergencia de nuevos paradigmas culturales". Por medio de este apartado, la filosofa abre el espacio de "cruce", que permite la convergencia entre las disciplinas que nacen al alero del enfoque científico de la antropología (estudios culturales) y la filosofía, cuestión que va transformando la conceptualización de cultura y de civilización, lo que a su vez permite el surgimiento de una filosofía conflictuada frente a su pasado aristocrático, geopolíticamente situado, hasta ahora siempre presente. El desafío radica en lograr "disminuir sus "decretos" de universalidad", para ello "una nueva filosofía de la cultura" debe apuntar hacia "un nuevo estilo y un método de aproximación a otras culturas, considerán- dola sujetos activos". En definitiva la filosofía se ve enfrentada al segundo momento crítico al interior de la noción de cultura, ahora en es en términos dialécticos en función de una filosofía que se hace cargo de su "dimensión dinámica".

Tras la perspectiva filosófica de la autora, que hemos desarrollado muy sumariamente, podemos distinguir que al hacerse cargo de la dimensión dinámica cultura, como efecto de la experiencia descentralizadora de las seguridades conceptuales y teóricas propias de la biografía filosófica occidental, nos encontramos a las puertas de una concepción débil de la cultura "que nos pone de manifiesto la necesidad de apertura y aceptación del cambio, como previo requisito para entrar en contacto con otras culturas, frente a las interrogantes que nos despiertan", lo que pone de manifiesto "el formato multicultural de las sociedades".

Lo que revive el problema para la filosofía, el problema por una ética universal, pero en clave de una sociedad multicultural, De Vallescar junto a Mall, plantea la necesidad de "una racionalidad universal, situada mas no local". Cómo hacer frente a este problema. La autora nos propone los trabajos, que tras el estudio presentado a lo largo del texto, se presentan como los filósofos que han desarrollado un marco metodológico y teórico más consistente en clave intercultural; el filósofo cubano Fornet-Betancourt y el filósofo español-hindú R. Panikkar. Estos autores vienen a dar respuesta al problema de una racionalidad universal discutido previamente en el debate entre Ch. Taylor y Habermas (Comunitaritas y liberales). Se trata de trasladar el debate desde el enfoque multicultural hacia una filosofía intercultural, para ello, el paradigma interreligioso-intercultural de Panikkar y el paradigma liberador-intercultural de Fornet, por lo que la respuesta al problema de una racionalidad universal se encuentra directamente relacionado a una revolución cognitiva en el campo del conocimiento, pero paralelamente vivida en un diálogo concreto. 